When to all this is added the distinct possibility of language difficulties and methods of expression or of misinterpretation of the radar picture, it is difficult to avoid the conclusion that silence would be golden and speed reduction a better risk than talk.

\title{
Radar Displays
}

$$
\text { from J. A. Glasgow }
$$

IN a recent contribution to Forum by Commandant L. Oudet (Journal, 17, 88) the problem of the rational form that marine radar displays should take has been raised. The old argument of 'ship's head upwards' or 'north upwards' may be resolved by a combination of the best of both systems without compromise to either school of thought.

Before starting on how this may be achieved a short digression on terminology should not be out of place. The advantages in the use of a 'north upwards' display, i.e. true bearings, lack of smear, accurate plotting and the ability to add 'true motion' do not stem fundamentally from the fact that north is at the top but because the picture is 'compass stabilized'. The 'north up' condition is purely a matter of convenience. The 'north upwards' display would be better termed 'compass stabilized north upwards'.

The type of display that Commandant Oudet calls for is one in which the navigator would see the screen just as he sees the compass card or the sea-scape around him'. The point to be taken from this is that the compass card is naturally compass stabilized and also that on changing course the ship rotates round the compass card, i.e. the compass rotates relative to the ship. To obtain the best radar presentation these two requirements must be met-first of all, the display must be compass stabilized and, secondly, it must be capable of the proper rotation as and when the ship changes her heading. The result is a "compass stabilized ship's head upwards' display. This will give the ease of interpretation of a 'ship's head upwards' display together with true bearings, no smear, true motion if required and also accurate plotting which maintains its validity during yawing and changes in course.

Such a display (the 'Argus') has been developed by the Marconi Company and is already in use at sea. In this particular equipment the operation may be described quite simply. First, the tube, bearing scale and plotter (if fitted) are fixed together but are capable of rotating within the display unit under the control of the compass transmitter. Secondly the c.r.t. trace itself is compass stabilized. Assume as a start that the $0^{\circ}$ or North on the bearing scale is at the top of the display and the tube is held stationary. A conventional 'compass stabilized north upwards' display is now seen and the heading line will show the true direction of the ship's head. The whole assembly of c.r.t., bearing scale and plotter is now rotated until the heading line is upwards. On changing course the transmitting compass now stabilizes not only the trace on the tube but also the tube in the display unit. It is the combination of these actions together that gives the required display, i.e. 'Compass stabilized ship's head up'. 
This would appear to be the right form of presentation of radar in the wheelhouse where the natural orientation of the radar targets to the position of the ship's head is most important for the purpose of collision avoidance. Even whilst taking avoiding action the situation is clearly seen, without confusion due to the clarity of the screen and lack of smear. For those times when a radar fix is to be transferred to a chart the tube can be made to revert to 'north upwards' for a quick visual comparison. The 'ship's head up/north up' switch only controls the tube position, not the radar information on the tube. On switching from one presentation to the other the tube rotates with the unsmeared picture on it, giving a clear picture at all times.

\section{Ministry of Transport Examinations \\ from Captain G. E. Stephenson}

If the day is not far off when communication satellites will lessen a navigator's dependence on conventional astronomical aids it is surely overdue for the deletion of obsolescent and superfluous items from the M.O.T. syllabus for candidates.

Of the three 'standard' formulae for finding a position line from an altitude of a celestial body (ex observer's meridian) only one, Marcq St. Hilaire, is in general use at sea today. The other two, Longitude by Chronometer and Latitude by Ex-meridian, depend for survival on the patronage of the Ministry of Transport and the Nautical Schools.

The M.O.T. still requires the candidate to name two points on the position line, neither of which in practice is considered to be the observer's most likely position, but he has always been free to choose his own means of finding these points.

It is regrettable that such liberty of choice is denied to students in our Nautical Training Schools who insist that three alternative methods of solving the triangle should be learnt.

The use of radar in conjunction with single visual bearings and the increased numbers of radio beacons operating continuously have deprived the transferred position line of most of its former glory. Its last stronghold is the noon 'position' when this is obtained from use of a single body. Position lines derived from star observations are now universally computed by the intercept method, regardless of azimuth or adjacency to the meridian or prime vertical.

If the use of this omnicompetent formula were accepted in its entirety by the Ministry of Transport it would remove hereditary misconceptions of the value of a single observation, and a quite unnecessary burden from the minds of aspiring navigators.

The 'Longitude' by Chronometer and 'Latitude' by Ex-meridian should be confined forthwith to the lumber room of Victoriana, with the legendary arts of rigging jury rudders, parbuckling pole-shaped objects up a ship's side, lowering 